\title{
Phylogenetic analysis of target of rapamycin (TOR) kinase gene of some selected plants species
}

\author{
Swapnil Sapre, Sharad Tiwari and Vishwa Vijay Thakur \\ Biotechnology Centre, Jawaharlal Nehru Agriculture University, Jabalpur 482004, India
}

\begin{abstract}
TOR kinase has been reported to regulate number of biological processes, including central dogma, which collectively contributes to cell growth in all the organisms. The major role of the target of rapamycin (TOR) kinase is to encourage cell growth in response to favorable conditions. Up to some extent,nucleotide and amino acidsequencesof TOR kinase were found to be similar in all the organismswherein it has been identified or characterized.In order to assess the phylogenetic relationship and conservative nature of TOR gene among 32 different plants species TOR gene sequences and protein sequence retrieve from public repository database NCBI.Sequence length and GC\% of each sequence were determined. Maximum GC\% was found in TOR kinase gene of Brachypodium distachyon (46.18\%). All the 32 TOR gene sequences contained more than 43\% of GC. Phylogenetic tree constructed using Neighbor-joining method separated TOR kinase into two distinct groups i.e. monocots and dicots. Sequences of TOR kinase from similar family of plants were grouped together signifyingits conserved nature within the family. The phylogenetic tree of TOR gene at both nucleotides and proteins level from different species perfectly reflects phylogenetic relationships of the species. This strong conservation of tor genes among all the species including in this investigation advocate the general significance of this kinase and, consequently, the entire TOR pathway.
\end{abstract}

KEY WORDS: CELL GROWTH; NEIGHBOR-JOINING; PHYLOGENETIC TREE; TOR KINASE

\section{INTRODUCTION}

The modulation of growth rate in a particular environmental condition such as nutrient availabilityis necessary for continued existence. Plant growth is largely

\section{ARTICLE INFORMATION:}

*Corresponding Author: swapnil.spr@gmail.com Received 20 $0^{\text {th }}$ April, 2018

Accepted after revision $21^{\text {st }}$ July, 2018

BBRC Print ISSN: 0974-6455

Online ISSN: 2321-4007 CODEN: USA BBRCBA

\%.: Thomson Reuters ISI ESC / Clarivate Analytics USA and

: Crossref Indexed Journal

NAAS Journal Score 2018: 4.31 SJIF 2017: 4.196

- A Society of Science and Nature Publication, Bhopal India 2018. All rights reserved.

Online Contents Available at: http//www.bbrc.in/

DOI: $10.21786 / \mathrm{bbrc} / 11.3 / 17$ dependent on surrounding environmental information. It includes cell growth coupled with cell proliferation and cell expansion depends onexogenous factors such as stresses and nutrient availability. Unlike animals, in plants, postembryonic growth is directly influenced 
by availability of nutrients and energy source that are present outwardly or generated by various cellular processes (Nanjareddy et al. 2016). However, so far, very few secrets have been revealed on mechanism that how this information is perceived and transduce into coherent growth and developmental decisions. One of the most important pathways that are found in all eukaryotes is the one related to the target of rapamycin (TOR) protein kinase.

The target of rapamycin (TOR), a Ser/Thr protein kinase, has emerged as a key player of nutrient, energy, and stress signaling networks (Dobrenel et al. 2013; Yuan et al. 2013). It is a large protein that belongs to the phosphoinositide 3-kinase-related kinase family and is highly conserved among all eukaryotes (Robaglia et al. 2012). Numerous components of the TOR signalingmachinery have beenidentified in model plant Arabidopsis. Various members of the TOR complex such as the RAPTOR1/RAPTOR2, LST8-1/LST8-2, S6K1/S6K2, ribosome protein small subunit6 (RPS6A/B), type 2A-phosphataseassociated protein $46 \mathrm{kD}$ (TAP46), and ErbB-3 epidermal growth factor receptor binding protein have been reported in photosynthetic eukaryotes through sequence homology searches from $C$. reinhardtii to Arabidopsis plants (Creff et al. 2010; Ahn et al. 2011; Moreau et al. 2012; Ren et al. 2012; Xiong and Sheen, 2012).

In this era of high throughput gene and genome sequencing, prediction of function of a gene is a key step. Various reverse genetics techniques like site directed mutagenesis and RNAi are effective to solve this purpose. Another easier way to predict function of a particular gene and phylogenetic relation between different species iswith the use of bioinformatics. Nowadays, increasing sequenced genomesof diverse plants are providing new opportunities to study gene families in an evolutionary context. Based on these facts, present investigation was conducted to evaluate the phylogenetic relationship and sequence similarity of TOR kinase genes from different plants species and make an efforts to know the conserve nature of TOR gene at both nucleotide and protein sequence level. Phylogenetic tree analysis on basis of conserved nature and similarity of known sequence helps us to predict the function of a gene and also exhibit the phylogenetic relationships of the species (John et al. 2011). However, for a deeper understanding of the gene function, it is helpful to go beyond cataloguing of similarities and differences and to understand how and even why these similarities and differences arise.

\section{MATERIAL AND METHODS}

Nucleotide sequence of TOR kinase gene of Zea mays was retrieved from NCBI database for its further use as bait sequence to isolate other sequences of different plant species using BLASTn (http://www.ncbi.nlm.nih. gov/BLAST/). TOR gene nucleotide sequences of different plants were selected on the basis of E-value (within 0 to $1 \mathrm{e}-50)$. DNA sequences were aligned with ClustalW (Thompson et al. 1994) and alignments were subsequently adjusted manually using BioEdit (Hall, 1999). Sequence length and GC\% of each sequencewas calculated by MEGA6 (Tamura et al. 2011). Protein sequences were also deduced from all retrieved sequences of TOR kinase genes and were aligned using ClustalW and go for construction of phylogenetic tree.

To evaluate the genetic relationship between retrieved nucleotide sequences of TOR kinase gene, a phylogenetic tree was constructed using Neighbor-joining (NJ) method. The output data was processed using MEGA 6 to draw the phylogenetic tree. The bootstrap consensus tree (Felsenstein, 1985) inferred from 1000 replicates was selected to represent the evolutionary history of the 32 TOR kinase genes under study. Phylogenetic tree was also constructed for amino acid sequences of TOR kinase genes two know the sequence homology at protein level.

\section{RESULTS AND DISCUSSION}

In this study, TOR kinase gene sequences of 32 plants species belongs to 11 familieswere selected and retrieved from GenBank for phylogenetic analysis. The sequence lengths of all the TOR genes with GC\% are given in Table 1. Maximum GC\% was found in TOR kinase gene of Brachypodium distachyon (46.18\%). All the 32 TOR gene sequences containedmore than $43 \%$ of GC.

The evolutionary relationships between the plants were evaluated by phylogenetic analysis of the aligned nucleotides and amino acids sequence of their TOR kinase gene. TOR kinase gene sequences currently available in the database are either full length mRNA sequences or predicted sequences obtained from annotation of genome. The phylogenetic tree obtained by Neighborjoining method showed two distinctphylo-groups of TOR kinase genes from monocots and dicots (Fig 1). Group I containing only monocots included Zea mays, Setaria italica, Sorghum bicolor, Brachypodium distachyon, Oryza sativa, Oryza brachyantha, Phoenix dactylifera, Elaeis guineensis and Musa acuminate. Cluster of monocots further divided in two subgroups, wherein subgroup I-acontained three gene sequences, two from family Arecaceae and one from family Musaceae. The plant species Elaesis guineensis and Phoenixdactylifera belongs to same family Arecaceae and also exhibited high degree of similarity than plant species Musaacuminata belongs to family Musaceae in subgroup I-a.

This result also revealed that the relatedness of these two families were higher than the other family included in the present studies. While, subgroup I-b comprised 7 


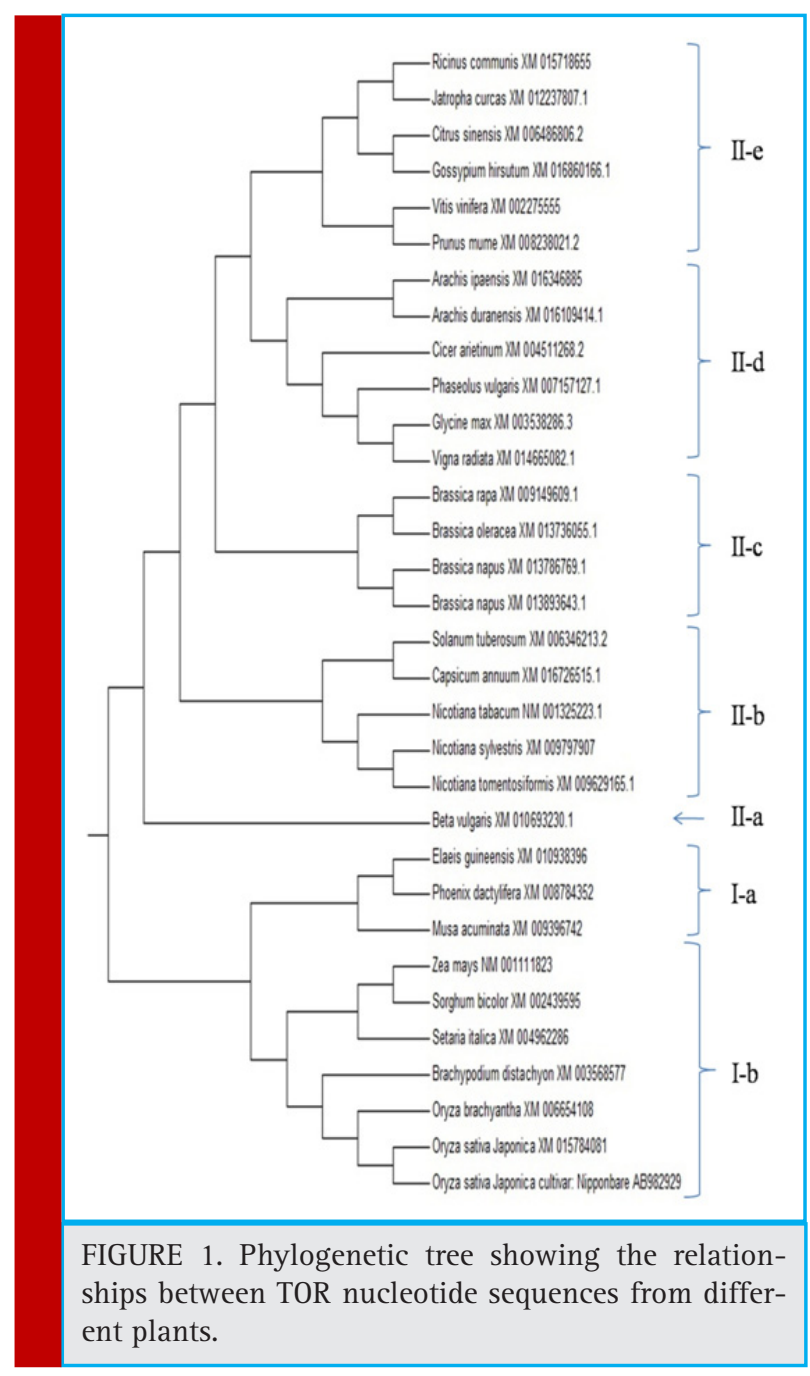

sequences,all belongs to Poaceae family. In this group the plant species of genus Oryza is closely related with Bracypodiumdistachyon while Zeamay sexhibited higher similarity with plant species Sorghum bicolor and Setaria italica. In group II, all the sequences of TOR kinase gene of dicot plants clustered into 5 subgroups. TOR gene sequence of Beta vulgaris was lone species in subgroup II-a whereas, remaining 4 subgroups clustered according to their family such as subgroup II-b consist of 5 species of Solanaceae, Subgroup II-cwas occupied bythe 4 species of Brasicaceae while 6 species of Fabaceae family gathered in subgroup II-d. On the other hand, five families namely Euphorbiacea, Malvaceae, Rootaceae, Rosaceae and Vitaceae grouped into subgroupII-e.

Inphylogenetic tree of amino acid sequences of TOR kinase divided into two groups of monocots and dicots (Fig 2) with a similar clustering pattern to nucleotide sequenc eexcept Vitis vinifera which formed a separate group II-d in phylogenetic tree of protein sequences. In group I of monocots, two subgroups of 7 and 3 plants

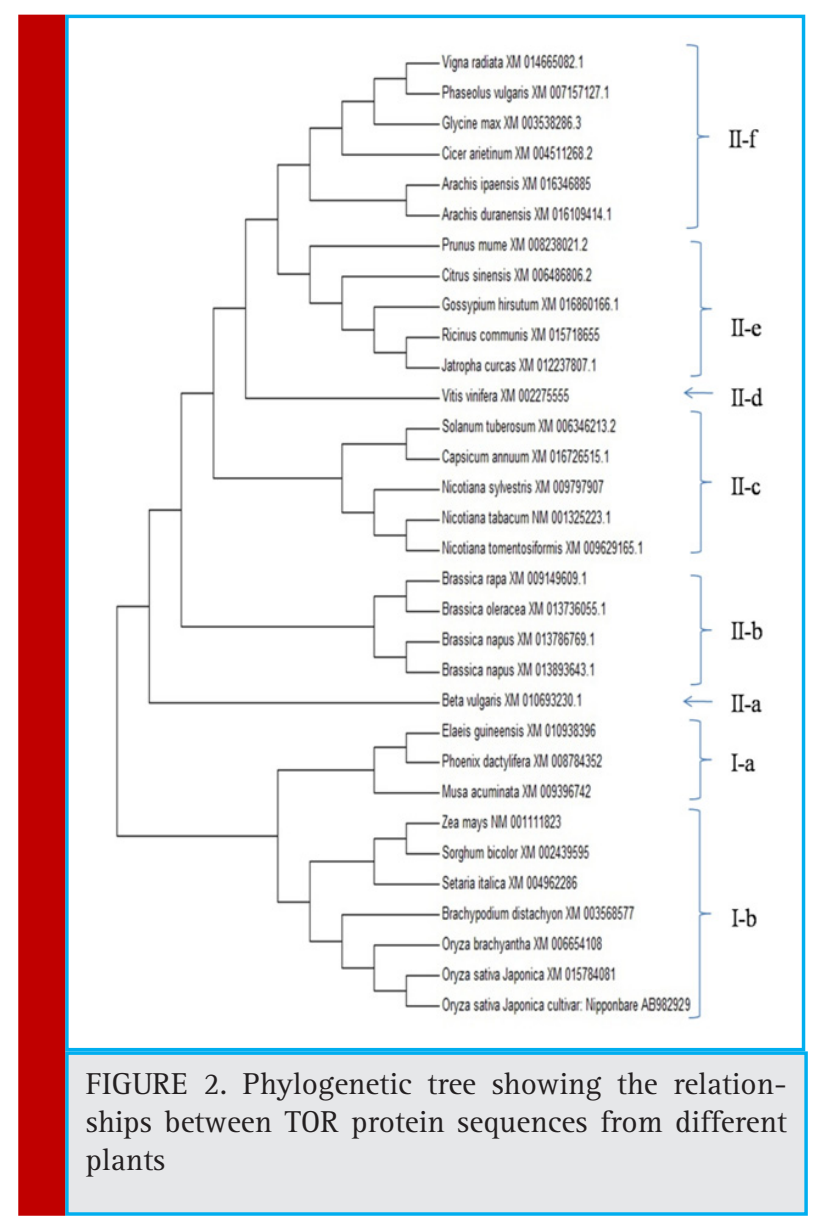

were formed. In group II of dicots, six subgroups were formed. Vitis vinifera and Beta vulgaris fell into two separate groups whereas, other groups contained 4,5 and 6 species of Brasicaceae, Solanaceae and Fabaceae respectively whereas, 5 genera clustered inII-e. Above mentioned results showed the highly conserved nature of TOR gene among different plant species at family level. The results obtained are in accordance with previous research finding reported by John et al. (2011) as they observed similar pattern of clustering during phylogenetic analysis of TOR proteins of different species included animal kingdom, fungi, algae and higher plants. In higher plants all the studied plants species are separated into two cluster i.e. monocots and dicots. The plants species Oryzasativa, Sorghum bicolor and Zea mays clustered together exhibited the similarity of results obtained during present studies. The amino acid sequences were found to be conserved among a wide variety of plants including all the cereals andin many dicots. Our results are also supported by another investigation carried out by Dobrenel et al. (2011) in which protein sequences of TOR kinase from plants, animals, yeasts, algae and moss were aligned and monocots and dicotsgrouped in separate clusters. The plants species 


\begin{tabular}{|c|c|c|c|c|}
\hline Plant & Accession number & Family & Size (bp) & $\mathrm{GC} \%$ \\
\hline Zea mays & NM_001111823 & Poaceae & 7691 & 44.80 \\
\hline Nicotiana sylvestris & XM_009797907 & Solanaceae & 6552 & 43.86 \\
\hline Setaria italica & XM_004962286 & Poaceae & 7899 & 45.80 \\
\hline Sorghum bicolor & XM_002439595 & Poaceae & 7544 & 44.55 \\
\hline Brachypodium distachyon & XM_003568577 & Poaceae & 8263 & 46.18 \\
\hline Oryza sativa & XM_015784081 & Poaceae & 7659 & 45.05 \\
\hline Oryza brachyantha & XM_006654108 & Poaceae & 7708 & 44.75 \\
\hline Oryza sativa & AB982929 & Poaceae & 7398 & 44.59 \\
\hline Elaeisguineensis & XM_010938396 & Arecaceae & 7722 & 44.28 \\
\hline Musa acuminata & XM_009396742 & Musaceae & 7722 & 44.51 \\
\hline Vitisvinifera & XM_002275555 & Vitaceae & 7791 & 44.15 \\
\hline Phoenix dactylifera & XM_008784352 & Arecaceae & 3530 & 43.63 \\
\hline Ricinuscommunis & XM_015718655 & Euphorbiaceae & 7993 & 43.69 \\
\hline Arachisipaensis & XM_016346885 & Fabaceae & 8105 & 44.45 \\
\hline Nicotiana tabacum & NM_001325223.1 & Solanaceae & 7488 & 44.78 \\
\hline Solanum tuberosum & XM_006346213.2 & Solanaceae & 7929 & 43.93 \\
\hline Capsicum аппиит & XM_016726515.1 & Solanaceae & 7581 & 44.00 \\
\hline Citrus sinensis & XM_006486806.2 & Rutaceae & 7929 & 43.65 \\
\hline Nicotiana tomentosiformis & XM_009629165.1 & Solanaceae & 6982 & 43.81 \\
\hline Jatropha curcas & XM_012237807.1 & Euphorbiaceae & 6910 & 43.14 \\
\hline Gossypiumhirsutum & XM_016860166.1 & Malvaceae & 7904 & 44.00 \\
\hline Arachisduranensis & XM_016109414.1 & Fabaceae & 8144 & 44.51 \\
\hline Prunusmume & XM_008238021.2 & Rosaceae & 7991 & 44.50 \\
\hline Glycine $\max$ & XM_003538286.3 & Fabaceae & 8287 & 42.97 \\
\hline Vigna radiata & XM_014665082.1 & Fabaceae & 8372 & 43.11 \\
\hline Cicer arietinum & XM_004511268.2 & Fabaceae & 8411 & 42.42 \\
\hline Beta vulgaris & XM_010693230.1 & Amaranthaceae & 8031 & 43.71 \\
\hline Brassica rapa & XM_009149609.1 & Brassicaceae & 7800 & 44.44 \\
\hline Brassica napus & XM_013786769.1 & Brassicaceae & 7581 & 44.60 \\
\hline Brassica napus & XM_013893643.1 & Brassicaceae & 7880 & 44.37 \\
\hline Brassica oleracea & XM_013736055.1 & Brassicaceae & 7630 & 44.39 \\
\hline Phaseolus vulgaris & XM_007157127.1 & Fabaceae & 4186 & 43.17 \\
\hline
\end{tabular}

Oryza sativa subsp. Japonica, Oryza sativa subsp. Indica, Bracypodiumdistachyon, Sorghum bicolor and Zea Maysare grouped together and formed the separate cluster of monocot species which showed similarity with results obtained during present investigation.

During phylogenetic analysis and sequence similarity search of wheat TOR gene with other plant species Sapre et al. (2016) observed the same clustering pattern of plant species as obtained in this investigation. The results of this investigation are not contradicted the results obtained by Nanjareddy et al. (2016) during the phylogenetic analysis of bean TOR gene which confirmed that this gene belongs to the legume group and is closely related to the G. $\max$ and M. truncatula TOR genes which showed the highly conserved nature of TOR gene at family level. In our studies all the plants species including in present investigation are clustered together according to their family showed the similar nature of gene as mentioned by Nanjareddy et al. (2016).

\section{CONCLUSION}

During present investigation phylogenetic analysis was carried out separately among TOR kinase gene sequences and amino acid sequences of 32 plants retrieve from public repository database NCBI. The phylogenetic tree of 
TOR gene and its homolog's from several plants including both monocots and dicots revealed a close relationship between plant species.All sequences were grouped separately in two groups i.e. monocots and dicots. Further, sequences from similar family grouped together perfectly reflect the conserve nature of TOR kinase gene at nucleotide and protein sequence level.This strong conservation of TOR geneamong all the studied plant speciesadvocates the general significance of this kinase and, consequently,the entire TOR pathway.

\section{REFERENCES}

Ahn CS, Han JA, Lee HS, Lee S, Pai HS (2011) The PP2A regulatory subunit Tap46, a component of the TOR signaling pathway, modulates growth and metabolism in plants. Plant Cell 23:185-209

Creff A, Sormani R, Desnos T (2010) The two Arabidopsis RPS6 genes, encoding for cytoplasmic ribosomal proteins S6, are functionally equivalent. Plant Mol. Biol. 73: 533-546

Dobrenel T, Marchive C, Azzopardi M, Clément G, Moreau M, Sormani R, Robaglia C, Meyer C (2013) Sugar metabolism and the plant target of rapamycin kinase: a sweet operaTOR? Front. Plant Sci. 4: 93

Dobrenel T, Marchive C, Sormani R, Moreau M, Mozzo M, Montane M, Menand B, Robaglia C, Meyer C (2011) Regulation of plant growth and metabolism by the TOR kinase. Biochem. Soc. Trans.39:477-481

Felsenstein J (1985) Confidence limits on phylogenies: An approach using the bootstrap. Evolution 39:783-791

Hall TA (1999) BioEdit: a user-friendly biological sequence alignment editor and analysis program for Windows 95/98/NT. Nucleic Acids Symp. Ser. 41:95-98 http://www.ncbi.nlm.nih.gov/ BLAST

John F, Roffler S, Wicker T, Ringli C (2011) Plant TOR signaling components. Plant Signal. Behav. 6:1700-1705
Moreau M, Azzopardi M, Clement G, Dobrenel T, Marchive C, Renne C, Martin-Magniette ML, Taconnat L, Renou JP, Robaglia C, Meyer C (2012) Mutations in the Arabidopsis homolog of LST8/GbL, a partner of the target of Rapamycin kinase, impair plant growth, flowering, and metabolic adaptation to long days. Plant Cell 24:463-481

Nanjareddy K, Blanco L, Arthikala MK, Alvarado-Affantranger X., Quinto C, Sanchez F, Lara M (2016) A legume TOR protein kinase regulates rhizobium symbiosis and is essential for infection and nodule development. Plant Physiol. 172:2002-2020

Ren M, Venglat P, Qiu S, Feng L, Cao Y, Wang E, Xiang D, Wang J, Alexander D, Chalivendra S, Logan D, Mattoo A, Selvaraj G, Datla R (2012) Target of rapamycin signaling regulates metabolism, growth, and life span in Arabidopsis. Plant Cell 24: $4850-4874$

Robaglia C, Thomas M, Meyer C (2012) Sensing nutrient and energy status by SnRK1 and TOR kinases. Curr. Opin. Plant Biol. 15:301-307

Sapre S, Tiwari S, Thakur VV, Tripathi N (2016) Molecular characterization and sequence identification of TOR kinase gene from wheat (Triticum aestivum). Adv. Life Sci. 5(12): 4819-4822

Tamura K, Peterson D, Peterson N, Stecher G, Nei M, Kumar S (2011) MEGA5: Molecular evolutionary genetics analysis using maximum likelihood, evolutionary distance and maximum parsimony methods. Mol. Biol. Evol.28:2731-2739

Thompson JD, Higgins DG, Gibson TJ (1994) CLUSTAL W: improving the sensitivity of progressive multiple sequence alignment through sequence weighting, position-specific gap penalties and weight matrix choice. Nucl. Acids Res. 22:46734680

Xiong Y, Sheen J (2012) Rapamycin and glucose-target of rapamycin (TOR) protein signaling in plants. J. Biol. Chem. 287: 2836-2842

Yuan HX, Xiong Y, Guan KL (2013) Nutrient sensing, metabolism and cell growth control. Mol. Cell 49: 379-387 